Anthropology Matters J ournal 2005, Vol 7 (2)

\title{
Pluralism, parallel medical practices and the question of tension:
}

\section{the Philippines experience}

\author{
Md. Nazrul Islam (Department of Sociology, University of Hong Kong)
}

Pluralism and the co-existence of a variety of different medical systems within a chosen context are common features in various settings. How do the different systems or practices interact? Is it plausible to develop an integrated health system (combining both biomedical and alternative medicines) within the national system in a medically pluralist society? This study was set in the urban slum of Balubad, located in Marikina city, The Philippines. It employed qualitative research methods, including individual interviews with a semi-structured questionnaire, and informal discussions. Two categories of respondent were selected by systematic and purposive sampling, and included community female and male respondents and practitioners of different healing systems. I found three significant trends: firstly, biomedical and alternative health practices exist in parallel but not are mixed. Secondly, there is little possibility of biomedical and alternative health professionals working together; they prefer to stay separate. Finally, although there is enormous socio-economic disparity between biomedical professionals and alternative healers, there is no tension between the two groups.

\section{Introduction}

Early medical anthropology paid much attention to the ethnographic study of 'indigenous' modes of healing and their relationship to underlying conceptualizations of sickness and health as part of a particular world view. This tradition was shifted gradually to consider other possible factors: biomedical hegemony in non-Western societies, for example, or the political economy of medical anthropology. Increasingly, however, research in non-Western settings has also turned to the study of medical pluralism, that is the co-existence of a variety of different medical traditions within a given context (Lambert 1998). Much attention has been paid to the description and comparative analysis of national 'medical systems' comprising a variety of forms of healthcare, and the degree to which these configurations can be considered 'systems' at all. An initial focus among applied anthropologists was local responses to biomedicine in non-Western settings and the putative conflict between different conceptual systems produced by this encounter. More recent work, however, places the changing relations between biomedicine and indigenous medical traditions (and, especially, processes of professionalization among indigenous healers) within a broader social and historical context that gives proper weight to the influences of colonialism and state legislation (ibid).

It is, however, important to address the tension between biomedical and alternative health practices in a specific community. The co-existence of different health systems or practices may continue under different circumstances in various settings. This paper attempts to counter the influential mainstream conviction about the existence of tensions between modernity and 
traditionalism (Foster 1973) in a transitional community (where characteristics of the rural and urban exist in parallel). It focuses on how medical pluralism exists in a non-Western urban slum and on how the health providers (both modern and alternative) are unwilling to come together or reconcile each other without creating tension.

\section{Pluralism and parallel healing}

The term 'healing' evokes a variety of complex and overlapping treatment systems. Various medical anthropologists have created typologies that recognize the phenomenon of medical pluralism in complex societies. Based upon their geographic and cultural settings, Dunn (1976) delineated three types of medical systems: 1) local medical systems, 2) regional medical systems, and 3) the cosmopolitan medical system. Local medical systems are 'folk' or 'indigenous' medical systems of small-scale foraging, horticultural or pastoral societies, or peasant communities in state societies. Regional medical systems are systems distributed over a relatively large area. Examples of regional medical systems include Ayurvedic medicine and Unani medicine in South Asia. Cosmopolitan medicine refers to the global medical system or what commonly has been called 'scientific medicine' or 'modern medicine' (Dunn 1976, cited in Baer et al 1997: 9).

In the context of The Philippines, Jocano (1973, Erlinda et al 2001: 47) found that traditional medicine is very closely tied to the world of spirits, and that 'traditional healers are generally believed to be empowered by gods or spirits'. Magos (1992) highlighted that in some communities in the Visaysa, the traditional medical practitioners are called manugbulong. This is an umbrella term that covers the ma-aram (native priest), the paltera (midwife), the manughilot (traditional chiropractor or bone settler), and the herbolario (herbalist). Magos considered these indigenous healers as 'folk philosophers'. Erlinda et al (2001) point out that an interplay of traditional perceptions and modern or Western medical views influence the concept of health and illness of the people of Badeo in the Philippines. ${ }^{1}$ Traditions are strongly observed in order to maintain health. But with the increase in interactions with other communities and recent Western technological advances, 'scientific' explanations have already begun to influence old customs and traditions used in managing health. As with many other societies, the majority of people believe that certain diseases are caused by supernatural beings. Ceremonies and rituals are continually performed in an effort to cure sickness, enhance body functioning, promote health, secure good harvests and marriages, communicate with ancestors, and even to ensure that the dead take a safe trip to the afterlife.

Ardales and Harder (1998) discovered that the co-existence of modern and various traditional medicines in societies is a well-recorded phenomenon. This is particularly prevalent in societies where one medical system alone cannot adequately meet the health needs of the entire population. This is the case in the Philippines, where the ratio of available biomedical doctors to the total population is very low: about one doctor to 20,000 persons. They concluded that the knowledge of traditional and modern medicines, including the practices of each type, is found to be strong among Ilongos and Negrenses. ${ }^{2}$ Generally, both medical systems were favourably

\footnotetext{
${ }^{1}$ Badeo is located in the municipality of Kibungan in the province of Benguet, the Phillipines.

${ }^{2}$ These are ethnic groups.
} 
received by these people. Among the rural folks, however, traditional medicine takes priority over these modern medicines. Primarily, this is so because they are bound by strong cultural traditions: knowledge of traditional healers is first learned from and constantly practised by their parents, kin and forebears. In addition there are financial reasons and traditional healers are highly visible and convenient for rural patients. Although patients claim that they usually get traditional healers to take care of their own and their kin's illnesses, the majority of the subjects have favourable attitudes toward biomedicine and its doctors. The people, however, did not regard all traditional healers with confidence and support (ibid).

The broad objective of this paper is to explore the popular beliefs and treatment choices, and to investigate possible tensions among healers. Other primary foci are the survival of pluralism, peoples' interpretations and responses to illness, social determinants of healing choices, and interactions among different healers and biomedical professionals. I conducted fieldwork in an urban slum community in Balubad, located in Marikina City, Philippines from May-June 2003. Several sites were suggested for this fieldwork by the host institute (Institute of Philippines Culture) in Manila city. I chose this site because of the presence of a health centre in the slum community. I particularly considered the function of both biomedical and alternative health practices within a small slum setting.

The fieldwork was qualitative, and included individual interviews with semi-structured questionnaires, and informal discussions. Most of the interviews were conducted in English and the respondents were able to communicate fluently. However, the five interviews with alternative healers were taken in Tagalok with the help of a research assistant who acted as a translator during the interview. All the interviews were recorded for further reference. Two categories of respondents were selected by systematic and purposive sampling, and included women (9), men (6) from the community, and practitioners (9), for a total sample of 24. Male respondents were not accessible at home during the daytime and they usually came back in the late evening. Most of them were unwilling to talk in the evening due to stress, so I interviewed fewer community males. Married males and females with few children were considered as respondents for interview. Some elderly men and women were also considered as respondents. Health practitioners comprised biomedical doctors (2), alternative healers (5, two of them were also working as volunteers at the community health centre as a health worker and dental aid respectively), a voluntary health worker (1) and a drug store owner (1).

\section{Pluralism and choice of healers}

I found different healing practices in Balubad, which represent medical pluralism. Most of the community inhabitants have migrated from provincial areas and represent different ethnic identities. They have different healing practices and remedies. The city health centre represents the biomedical health system, and has a significant impact on the community. Modern physician and alternative healers co-exist in the community but do not interact directly. Six types of healing system function in parallel in the community. Firstly, the local biomedical health centre provides biomedical treatment and comprises a doctor and other health professionals including voluntary health workers, nurses, midwives, and drug store staff. Secondly, albolarios (sorcerers or shamans) provide spiritual practices. ${ }^{3}$ Thirdly, community albolarios and hilots provide herbal

\footnotetext{
${ }^{3}$ Albolario, hilot and mananawas are different kinds of alternative healer.
} 
remedies utilizing different plant leaves. Fourthly, grandparents, mothers or elderly persons provide home remedies with plant leaves, water, salt and so on. Fifthly, hilots provide massage practices. Finally, mananawas identify the location of evil spirits in the body. It is sometimes difficult to distinguish between hilots and albolarios. One clarification is that an albolario is a person who uses some spiritual healing, like sorcery, while a hilot usually uses massage, herbal plants or oil. Another explanation pointed out the further confusing factor that albolarios also use herbal plants and some hilots act as albolarios. Mananawas are totally different from hilots and albolarios. They usually do not use any medicinal plants or herbs; instead they use candles and fire. They burn the candle, make a picture of the sick person's physiology and identify the space in the picture where the evil sprit exists. Daly Crown ${ }^{4}$ was one of the voluntary health workers assigned by the city health office and also acts as an alternative healer.

'I am basically an albolario and herbal hilot. I learnt my practice from my father who was also an albolario. I started this practice when I was 12 years old and I am 53 now. During my childhood I lived in a remote area and there was no doctor available there. Peoples depended on different herbal medicines. Herbal and albolario is not the same. Albolario is a person, who helps to heal some people but herbal is a remedy or medicine compose to different leaves for fever or cold, oregano leaf for cough or sambong leaf for UTI (urinary track infection), etc. If there is no doctor the albolario takes the responsibility to heal people. I learnt my practice for helping other people. Usually I don't get any money. But if the patient is willing to give any donation I accept. There is no fixed amount or fee like doctor's visit. I show you my practice by treating a young girl. I did not ask money but her mother gave voluntarily and I accepted. If they don't give I never claim. I spent for healing kits (coconut shell, cero shin, candle, etc.) from my own pocket. I have herbal plantation in my home and don't need to buy anything for herbal medicine, but only preparatory kits. Usually peoples give some money but some also don't'.

Kleinman (1978: 422, cited in Helman 2001) suggested that, in looking at any complex society, one can identify three overlapping and interconnected sectors of health care; the 'popular' sector, the 'folk' sector and the 'professional' sector. The popular sector includes all the therapeutic options that people utilize, without any payment and without consulting either folk healers or medical practitioners. Among these options are: self-treatment or self-medication, advice or treatment given by a relative, friend, neighbour or workmate, or consultation with another lay person who has special experience of a particular disorder. The folk sector is especially large in non-industrialized societies; certain individuals specialize in forms of healing that are either sacred or secular, or a mixture of two. These healers are not part of the official medical system, and occupy an intermediate position between the popular and professional sectors (ibid). The professional sector comprises the organized, legally sanctioned healing professions, such as modern Western scientific medicine, also known as allopathy or biomedicine. In most countries a special form of health care-alternative or complimentary medicine-overlaps both folk and professional sectors (ibid).

There are two trends found in this study: firstly, poor people usually visit or choose the alternative healers, and the rich rely on modern medicine. In other words, economic affordability and the level of modern education make a difference in healer choice. Secondly, after the failure of alternative healing practices, poor people go to the modern physician. However, it is also

\footnotetext{
${ }^{4}$ The original names have not been used in this paper.
} 
evident in some cases that after the failure of a modern doctor, patients go to the alternative healers, albolarios for spiritual healing or herbal remedy, even when they have a modern education and money. Some patients really trust the power of albolarios though they hold sufficient money and a modern education. For instance, some provocative alternative healers pointed out that their patients had chosen them after unsuccessful visits to the doctor or health centre where the remedies given by the doctor did not heal them. During my interview with an albolario, Samia Paul was present as her patient. Samia is a student at the University of Philippines. She had some problem with bleeding and had already visited a modern physician. The doctor had performed an ultrasound and did not find any abnormality in her abdomen. Samia still thought she had some abnormality that could be healed. Her mother supported her wish to visit an albolario for spiritual healing. They found that a spirit, in the form of a man without a head playing the flute from the toilet at midnight, was the basic reason for Samia's difficulty. The albolario burned some coconut shell with ceresin, prayed in her supernatural speech and identified the evil spirit. She then burned the evil spirit and caressed all parts of Samia's body with her hand. After that the albolario gave the burned dust to Samia to keep secretly. Samia was satisfied. Her mother was happy.

\section{Becoming a doctor or healer}

Medical doctors are trained with 19 years of formal education, which is a prerequisite to becoming a physician in Philippines. It includes ten years of schooling, four years in college or University, four years in medical college and a one-year internship in a hospital or clinic. Voluntary health workers were chosen by the city health office on the basis of their knowledge about the community, willingness to help the people, previous experience and educational background (at least high school graduation). By comparison, alternative healers' professions were perceived as gifts from God, and they achieved their healing powers through dreams. A few alternative healers acquired healing expertise through practical experience working under parents or other ancestors. They became healers in response to a situational demand: most of them started healing once they were in a province where no other medical facilities were available. Most of them came into this profession in order to help people, touched by the helplessness of victims during sickness. However, some alternative healers did not come willingly into their profession but felt that God had selected them and that they are obeying the order of God. Novely Mai had been working for a long time as a hilot and providing different herbal remedies. She said,

'I learned healing from my father through observation. One of my siblings was also a hilot. When I was 23 years old and still unmarried I started to heal children and elderly people for influenza, fever, cough, dislocated bones and pregnancy. Once, when I was 43 years old, I was sleeping and in the middle of night an old woman came to me. I saw her in dream but I don't know where she came from or who she was. She just called my name and said, "Wake up! I will give you something, which can give you a better life." She did not introduce herself. She gave me small bag full of tree leaves and then someone took it from me. I saw, as my eyes were open. Since then my healing power started to become more and more powerful. I did not get the bag, as an invisible person took it from me. Basically, I am a hilot but also an albolario, as I use plants. The definition is when you are an albolario you should use plants but the hilot usually uses oil. Albolario is also spiritual healer. Sometimes the albolarios are different from each other. The albolario primarily prescribes herbal plant but hilot uses coconut oil, garlic, onion, etc. In certain cases, I also prescribe 
herbal plant when it is getting worse. In this sense I am also an albolario. I can not refuse people if someone comes to me for help or healing'.

\section{Pluralism and perception}

Most of the alternative healers noticed that generally physicians or biomedical doctors under this study do not respect, believe in, or rely on herbal remedies or albolarios. Medical doctors usually trust only the treatment they know. Alternative healers however, respect doctors' treatments. For instance, there is a hilot and an albolario working in the health centre but they usually do not suggest their way of healing in the centre due to their respect for doctors. One of them is working as a voluntary health worker and provides both spiritual and herbal remedies. She usually suggests that the patient visits her home or she visits the patient's home to provide remedies. Another alternative healer is a dental aide and offers massage in his leisure time, for instance during the lunch break or late afternoon when the doctors are not present, or when the health centre is less crowded. He also provides massage in his home. Both healers do not find any contradiction between their employment in the health centre and their private alternative practices. One of the major reasons to employ them in the health centre is their acceptability and exposure as a health worker in the community.

The two biomedical professionals interviewed have their own opinions about alternative healing and remedies. One of them perceives that the alternative healers do not have any scientific basis and should not be integrated in mainstream health. He believes that only the scientific system and medical doctors should survive and alternative systems must be stopped. They believe that spiritual practices in particular do not work and must be restricted. Another biomedical doctor supports an increase in the use of common herbal medicine and plants that help poor people to get easy access due to affordability. More studies should be conducted on alternative remedies so that, if they are found effective, we can incorporate them into the mainstream health policy, she added. Additionally, both the medical doctors pointed out three reasons to support the alternative healers, including affordability, the belief system and accessibility. Besides this, some community respondents who did not believe in albolarios, hilots and mananawas claimed that belief or faith is one of the major reasons for the existence of non-scientific or supernatural practices in the community. Inappropriate use of alternative remedies is another important concern. One medical professional thinks that if the spiritual healers take money from the patient, it is exploitation. The patients usually visit alternative healers due to economic reasons, as they do not have enough money for the medication or doctors' fees to get admitted to the hospital. Moreover, they worry if the doctors refer them to be admitted to the hospital and they are absent from work. The beliefs of parents and other householders, who advise them to go to taus, herbal healers, or hilots, are other key reasons to visit alternative healers. Poor people do not have a lot of time to follow the procedures that are required to visit modern doctors, such as getting a doctor's appointment and waiting, and so on. An alternative healer is available at any time.

\section{Integration}

Most of the community and health care respondents felt that modern physicians and alternative healers cannot work together and should stay separate. Very few respondents pointed out the prospect of working together. There are various causes. Firstly, modern doctors and alternative 
healers have different ways of healing, remedies, expertise and beliefs, which cannot be integrated. Secondly, physicians are educated and hold formal training which the hilot or albolarios do not. Thirdly, physicians do operations but alternative healers depend on only medicine, massage or spiritual healing. Finally, usually the poor people who visit albolarios or hilots cannot afford to see a physician. All the alternative healers noted that they also suggest to the patient to go to the doctor, but it is never reported to happen vice-versa. However, the health centre can invite the alternative healers to share their knowledge about healing procedures and people can understand easily their expertise and acumen, some respondents added. The alternative healers I interviewed are unwilling to be integrated with the modern health system. They do not even expect any help from their government for their healing practice. A strong voice from the community advocates that alternative healers should not be connected with the national health system or city health centre.

\section{Socio-economic dynamics}

Most of the community respondents think that formal education persists as a basis of hierarchy between biomedical doctors and alternative healers. There are two reasons for this: the amount of resources required for biomedical education in the Philippines, and the lack of a formal training/study program for alternative healers. In the Philippines, medical education is directly associated with large amounts of money. Most of the medical colleges operate privately and consequently only rich people can afford to pursue their study there. Also, a medical education takes twice as long as a college/university education. Absence of any study curriculum or formal training program for alternative healers plays another key role in making a social difference between doctors and alternative healers. The biomedical system is a monopoly in mainstream health policy in the Philippines.

The difference in socio-economic status between biomedical health professionals and alternative healers is also an important concern. Biomedical professionals and alternative healers have different socio-economic circumstances. Alternative healers always interact with each other, and if they fail to heal patients, they hand over the charge to a more powerful healer. Different levels of professional expertise exist among alternative healers. Biomedical doctors, however, refer their patients to a specialist once the case is severe and never rely or refer to the alternative healers, though, some alternative healers suggest their patients go to the biomedical doctors if the case is getting worse.

\section{Lack of tension between alternative healers and mainstream health}

Among the health practitioner respondents, two are working in the health centre as a voluntary health worker and a dental aid, respectively. At the same time they are practising as a hilot and an albolario in the community. One of them told me that though the number of her patients is declining due to the establishment of the city health centre in the community, this does not create an uncomfortable situation for her. She does not prescribe anything or suggest her alternative remedies for the patients once she is in the health centre due to her respect for the medical doctors. However, she heals her family members and prescribes herbal medicine. Another alternative healer pointed out that he sometimes provides massages to his patients, even in the health centre, in an informal setting, during leisure time or late afternoon when the health centre 
is less crowded and doctors are out of the office. He also heals his family members and advises them to consult with a medical doctor if they are severely affected. Involvement in the city health centre or in mainstream health does not create any major impact on their alternative practices. Most of the alternative healers are comfortable with the presence of the health centre. It does have a negative impact on their patients or their practice. Most of the community respondents also find no tension between the biomedical and alternative healers, and the fact that they do their jobs in parallel.

\section{Conclusion}

Since the early 1960s, repeated failures of context-insensitive health programs in the nonWestern world have promoted a growing awareness of the need to attend to social and cultural dimensions of health in the health professions. This created an avenue for anthropologists to incorporate their expertise into mainstream health policy making and to work with multidisciplinary teams. The initial task assigned to the anthropologist was to identify 'cultural barriers' to modern health care and the means for overcoming resistance to change in nonWestern settings. Applied studies of this type argued for a greater degree of cultural sensitivity in the formulation and implementation of health education and disease prevention programmes imported from Western settings (Lambert, 1998). The idea of 'mainstreaming alternative healers' was also an outcome of the conceptual discrepancies and conflicts between local beliefs about the causation of illness and biomedical approaches to disease prevention.

My study elicited evidence that 'tension' among different healers who practice their expertise within the same community does not necessarily exist in all cases. Everybody appears strongly secure in their own business without creating any threats or inconvenience for others. It also seems to a certain extent that modern doctors perceive alternative practitioners negatively, but this does not produce any tension. Alternative healers are respectful of biomedical physicians and their practices because doctors are also seen as part of a modern society in which medical doctors are respected people. Since there is no discontent amongst the healers, finding a way of integrating different healing systems within a single national system is not essential for the community respondents and healers. Most of the healers I interviewed do not want to come together but would prefer to stay separate. The majority of community respondents also perceive that it is better if they stay separate.

The existence of different kinds of medical practices in the same community in a specific period of time is an indication of medical pluralism in a non-Western setting. Balubad is an example of a setting where home remedies, herbal, spiritual and biomedical systems function in parallel. The existence of different healers is another significant aspect of health-seeking behaviour in this urban slum area. The state's health policies can have a major impact thereon. In the case of the Philippines, the biomedical health system has a monopoly on state health policy, and there is no major training/academic program for the alternative healers but only for the biomedical professionals. Though a large number of alternative healers are practicing, serving a large number of patients every day, their system of health care exists only in a very scattered and individualistic form. There is no licensing, registration or legislation for them on the state level. This situation also increases the social differences between medical doctors and alternative healers. Modern doctors do not believe or rely on the expertise of alternative healers, thus they tend to ignore them. But it does not mean that this ignorance increases the tense situation between these two 
groups. Alternative healers are respectful towards the modern doctors, yet they do not want to be integrated in the mainstream health system. They prefer to stay parallel but separate.

\section{References}

Ardales, V.B. \& Harder, J.R. 1998. Knowledge, attitude and practices of traditional and modern medicines in Iloilo and Negros Occidental. A research project under Philippine Study on Community Participation in Essential National Health Research (ENHR). Philippines.

Baer, H.A. et al. 1997. Medical anthropology and the world system-a critical perspective. Westport, Conn.: Bergin \& Garvey Publishers.

Dunn, F.L. 1976. Traditional Asian medicine and cosmopolitan medicine as adaptive systems. In Asian medical systems: a contemporary study (ed) C. Leslie. Berkeley: University of California Press.

Erlinda, C.-P. et al. 2001. Mainstreaming indigenous health knowledge and practices. Centre for Integrative and Development Studies, University of Philippines, Daliman, Quezon City, Philippines.

Foster, G.M. 1973. Traditional societies and technological changes. New York: Harper \& Row

Helman, C.G. 2001. Culture, health and illness (Fourth edition). London: Arnold.

Jocano, F.L. 1973. Folk medicine in a Philippines municipality. Manila: The National Museum. Philippines.

Kleinman A. 1978. Problems and prospects in comparative cross-cultural medical and psychiatric studies. In Culture and healing in Asian societies (ed.) Kleinman A. et al. Cambridge, Massachusetts: Schenkman Publishing Company.

Lambert, H. 1998. Medical anthropology. In Encyclopaedia of social and cultural anthropology (eds.) A. Barnard \& J. Spencer. London: Routledge.

Magos, A. 1992. The enduring Ma-aram tradition. Quezon City: New Day Publishers.

\section{About the author}

Md. Nazrul Islam is currently completing his $\mathrm{PhD}$ in medical anthropology at the Department of Sociology, University of Hong Kong. Prior to this he was a German Academic Exchange Service (DAAD) Fellow in the Department of Tropical Hygiene and Public Health, University of Heidelberg during which time he undertook fieldwork in the Philippines. He can be contacted by e-mail: nazrul@hkusua.hku.hk. 